\title{
An encounter with Albania's best known drug addict
}

\author{
Philip M. Fleming
}

Albania borders the Adriatic Sea and lies between the former Yugoslavia to the north and Greece to the south. Seventy per cent of the land mass is mountainous, the coastal strip containing most of the country's agricultural land and having the densest population. The total population of the country is 3.4 million while the capital Tirana has a population of 250000 . Until very recently Albania was rarely visited by people from the West. It had become increasingly isolated under the Stalinist dictatorship of Enver Hoxha and the paranoid attitude towards foreigners that existed in the 1970s and 1980s is well illustrated by the concrete pill boxes that were built to repel invaders. More than 600000 of these were built and they can be seen today scarring the attractive

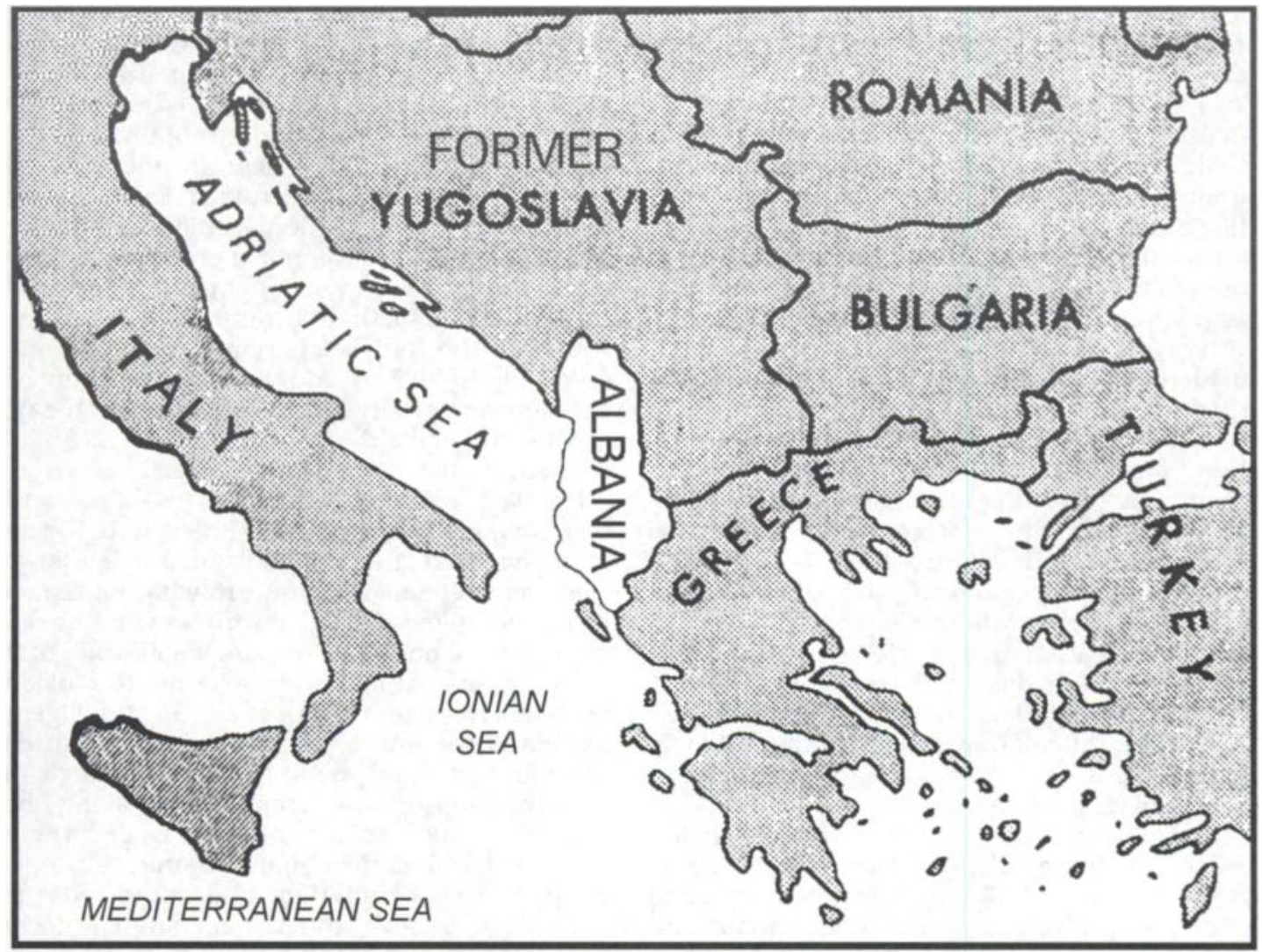

Map showing Albania in relation to other countries. 
countryside of hills and fields around Tirana. With the collapse of communism in Eastern Europe, Albania followed the same path and went through a period of disorganisation in 1991 before electing its first democratic government in 1992. As with other former communist countries private enterprise began to develop, land was sold back to the peasants, and private cars began to appear in the streets. In 1992 there were no private cars in the country; in 1995 there were 35000 in Tirana alone.

It was inevitable with the abolition of the police state and the freer movement across the borders that another accompaniment of western civilisation, drug trafficking, should begin. It was the concern of the Albanian authorities at the potential growth of drug misuse in the country that lead to my short visit in May 1995. I attended a seminar organised under the aegis of the World Health Organization to help the Albanians plan a strategy for dealing with drug misuse.

We learnt that the country is on the drug trafficking route from Italy to Eastern Europe and from South West Asia to Western Europe. Drugs are beginning to be produced in Albania, notably cannabis, which grows easily in the warm climate and some opium produced from indigenous poppies. But it is the contact with Italy, that most concerns the authorities. There is a major heroin problem in Italy, many Albanians have moved there in the search for a better life and some are returning with drugs. There is a real worry that the high incidence of HIV infection among injecting drug users in Italy will lead to the spread of the infection within the Albanian population there and that this will be imported into Albania by returning nationals.

Although the conditions exist for an increase in drug misuse in Albania there is not much evidence of this at present. No epidemiological studies have been undertaken and there have been very few reports of problem drug users presenting to medical services so it is difficult to be certain. All the same our impression was that at the time of our visit, perhaps uniquely in Europe, Albania did not have a significant drug problem.

However there were three addicts being treated by the local psychiatrists and one of these, whom I shall call Agim, was causing particular problems. We first heard about him during an initial briefing by the deputy Minister of Health, and he was mentioned several times during our seminar with the senior health and other officials. His plight had been the subject of media attention and he and his family had had an interview on two occasions with the Minister of Health. The Director of the University Psychiatric Clinic and the Chief of Adult Psychiatry, whose patient Agim was, asked if I would like to see him to give my views on his management.

Agim, now aged 29, his wife and two young children were living in a two-room flat in a building of the psychiatric clinic, under the office of the Director who was thus daily reminded of their presence. He had squatted in the empty flat a year earlier and no one had felt able to evict him. I saw him with his mother and wife and the two senior psychiatrists acted as interpreters. Agim had a criminal record and in his early 20s was convicted of murder and sent to prison. On release he was diagnosed as suffering from schizophrenia and spent a spell in a provincial mental hospital. However it may be that this diagnosis was given due to antisocial behaviour because there was no current evidence of mental disorder and he was not considered to be suffering from mental illness. After his discharge from psychiatric care he began in 1990 to use pethidine obtained on the black market and became increasingly involved in its use, injecting it regularly. In 1993 he approached the psychiatric clinic for help. Although he was not using it on a daily basis he persuaded the medical staff to prescribe him pethidine ampoules. Over the two years he had been treated his dose had gradually increased and when I saw Agim he was getting Seventy $50 \mathrm{mg}$ ampoules each day! His health had deteriorated and he had had numerous infections from injecting.

He was pyrexial when I saw him, with thrombophlebitis and no veins left to inject into; he said he injected intramuscularly. However no one could confirm what he did as he did not allow anyone to witness what he did with the ampoules. The suspicion was that some of his supply was sold on the black market. He came across as an intelligent manipulative character, whose story varied the more he was pressed. He complained of lack of appropriate treatment, saying he wanted to be treated abroad where there were better facilities. Agim's family strongly supported this and they had contacted the Minister of Health and the media. The local psychiatrists also wanted him treated abroad, perhaps to get him out of their hair. I gave advice about getting more control over the 


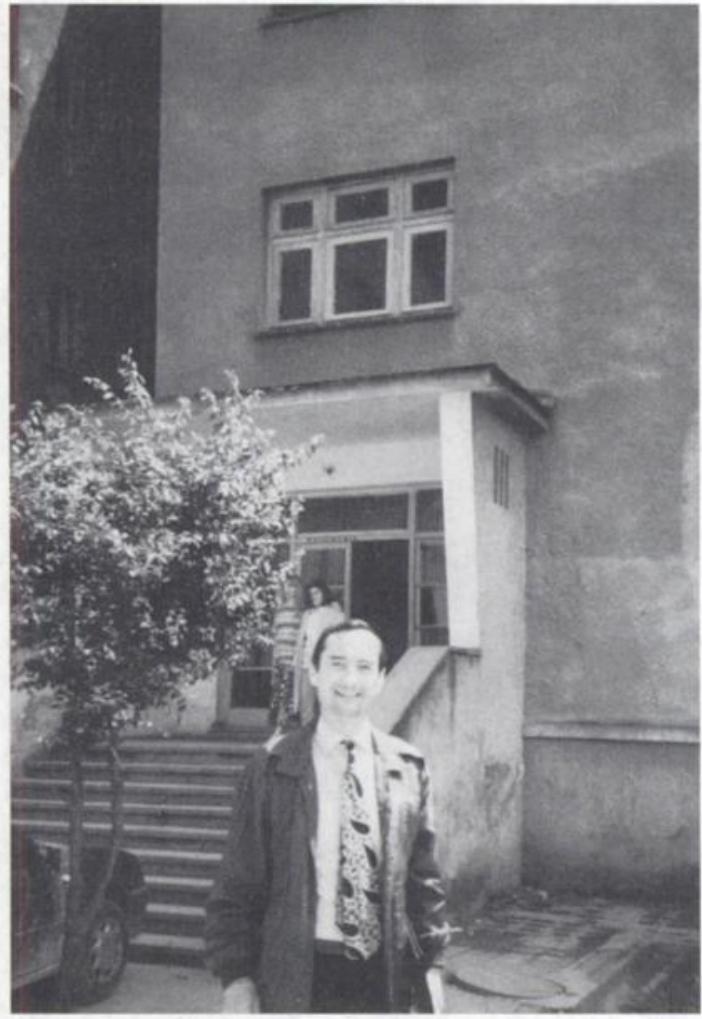

Dr Afrim Dangellia, Chief of Adult Psychiatry at the University Psychiatric Clinic in Tirana, standing in front of his unit.

situation, monitoring his drug use more closely and beginning a slow reduction. If he showed motivation to change I thought it reasonable to consider treatment somewhere like Italy, although it seemed an expensive precedent. This was the advice we gave to the Minister of Health.

What lessons are to be learnt from this case? I had wondered why the doctors had seemed so powerless in dealing with Agim. It emerged that they were frightened for their safety. Before his health had deteriorated he had been a large powerful man with many criminal contacts and both senior psychiatrists had received threats from him. After my encounter with him Agim's cousin had rung the Director of the clinic at his home pleading his cause for treatment overseas. But general principles apply: one should not embark on the treatment of addicts by replacement drugs without evidence of dependence, clear treatment goals, and close monitoring. The doctors concerned had had no previous experience or knowledge of addiction and had been manipulated by a clever operator.

The resources available for health care in a country such as Albania are very limited. Although life expectancy at 72.2 years is better than the average for countries of central and eastern Europe, the number of physicians, nurses and hospital beds per 100000 population are among the lowest in Europe. The lack of resources was brought home to me on a visit to the university adult psychiatry in-patient unit. The building was in an appalling state of repair with lumps of plaster falling off the walls, ill-fitting doors and looking more like an abandoned building than a hospital. The most distressing ward was for chronic patients, most with a diagnosis of schizophrenia. The furniture was sparse and patients had nowhere to go apart from their dormitories or the corridor. Most of the windows were broken so that the rooms were very cold in the winter months. Most patients were dozing on their beds; there was urine on the floors of some dormitories. The other wards were slightly less dilapidated, but patients were wandering about with nothing to occupy themselves. Psychotropic medication was available, mostly older major tranquillisers and tricyclic antidepressants. There were very few nurses and no specalised psychiatric training for the nurses. The psychiatrist in charge of the unit, Dr Afrim Dangellia, was well-informed and had visited psychiatric units in Germany and Denmark. He was only too aware of the deficiencies of the care available for his patients.

While the focus of our visit to Albania was drug misuse it was clear that the country is facing major economic and social problems. The Albanians we met were outgoing friendly people who seem optimistic about the future. Having endured nearly 50 years of one of the most repressive communist regimes the breath of freedom is still sweet.

Philip M. Fleming, Consultant Psychiatrist, Portsmouth City Drugs and Alcohol Service, Northern Road Clinic, Portsmouth PO6 3EP 